\title{
Resveratrol Supplementation Prevents Retinal Tissue Damage by Increasing Antioxidant Activity Through SIRT1 Gene Expression in Diabetic Elderly Female Rats.
}

\section{Adem Atacak}

Selcuk University, Medical Faculty

Saltuk Bugra Baltaci

Selcuk University, Medical Faculty

Elif Gulbahce-Mutlu

KTO Karatay Universitesi

Omer Unal

Selcuk University, Medical Faculty

Rasim Mogulkoc

Selcuk Universty, Medical Faculty

Abdulkerim Kasim Baltaci ( $\square$ baltaci@selcuk.edu.tr)

Selcuk University, Medical Faculty, Department of Physiology https://orcid.org/0000-0003-2461-1212

\section{Research Article}

Keywords: Diabetes, Retina, SIRT1, Tissue Damage, Resveratrol, Aged Female Rat.

Posted Date: June 7th, 2021

DOI: https://doi.org/10.21203/rs.3.rs-571981/v1

License: (c) (i) This work is licensed under a Creative Commons Attribution 4.0 International License.

Read Full License 


\section{Abstract}

The present study was carried out to investigate how resveratrol administration affects retinal SIRT-1 levels and retinal tissue damage in diabetic elderly female rats.

A total of 24 elder female rats were divided equally into 4 groups: 1, Control; 2, Control + Resveratrol; 3 , Diabetes; 4, Diabetes + Resveratrol. Experimental diabetes was induced by a single intraperitoneal injection of Streptozotocin (STZ) in Group 3 and 4. The group 2 and 4 given intraperitoneal (ip) RSV (5 $\mathrm{mg} / \mathrm{kg} / \mathrm{day}$ ) for 4 weeks in addition to the normal diet. After 4-weeks resveratrol treatment, SIRT1 gene expression and MDA ve GSH levels were determined by PCR and ELISA, respectively, in retinal tissue samples of the animals.

The highest retinal MDA values were in the diabetes group (G3), the highest retinal GSH levels were in the Diabetes + Resveratrol group (G4). The retinal MDA and GSH levels of the other groups were not different from each other. The highest retinal SIRT1 expression values were in the Diabetes + resveratrol (G4) group. The retinal SIRT1 expression values of the diabetes group (G3) were lower than group 4, and higher than the groups 1 and 2. Retinal SIRT1 expression values of the groups 1 and 2 were not different from each other.

Resveratrol supplementation prevented retinal tissue damage that occurs in diabetic aged female rats. This antidiabetic effect of resveratrol supplementation occurs by increasing both antioxidant activity and SIRT1 expression in diabetic aged rats.

\section{Key Points}

Resveratrol is a powerful stimulant of SIRT1 that prevents retinal damage.

\section{Introduction}

Diabetes mellitus (DM) is now recognized as a global public health problem. Diabetic retinopathy (DR), which is the leading cause of blindness in adult individuals, occurs as a result of a common complication of DM [1]. Diabetic patients may have multiple symptoms of eye diseases, including keratitis and DR, which accelerate the formation of cataracts. Therefore, if diabetic retinopathy is not tightly controlled, it can lead to permanent loss of visual function [30].

It has been reported that oxidative stress caused by high glucose levels can damage human lens epithelial cells and trigger cataract formation [10]. It is known that retinal tissue damage develops more rapidly in patients with DM [35]. In recent years, many treatment options have been developed for the late stages of diabetic retinopathy. These treatment options often target vasculopathy of the retina [1]. Treatment methods that can reduce the incidence and/or prevent the progression of DR, which is accepted as a common neurovascular complication of diabetes, are also very limited $[1,6]$. In DR, dysfunctions in neuronal and glial functions are generally considered to occur before vascular 
abnormalities. This is because it has been demonstrated in the investigation of retinal functions in both diabetic humans and experimental diabetic animal models $[1,6]$.

Resveratrol (RSV) (trans-3,4,5-trihydroxystylben), a polyphenol phytoalexin, is abundant in different plants such as grapes, peanuts and strawberries [24]. Resveratrol has been reported to have numerous biological functions due to its cardioprotective, anticoagulant, therapeutic effects on tumoral events as well as its preventive effects on tissue damage [9]. In recent years, the antidiabetic effect of RSV has been emphasized in the prevention or treatment of diabetes complications, including DR $[18,36]$.

Sirtuin 1 (SIRT1) is the most important sirtuin family member, affects cell aging, differentiation, apoptosis, and lipid and glucose metabolism $[8,19]$. SIRT1 can alleviate tissue damage in endothelial tissue as well as improve against vascular inflammation by preventing the decrease in vascular pressure. It may also protect against endothelial dysfunction [16]. Therefore, previous relevant studies have suggested that SIRT1 may restrict retinal vascular endothelial cell dysfunction under hyperglycemic state [17]. SIRT1 is also known to play a critical role in preventing DR [35]. Although the mechanism of SIRT1 in inhibiting DR has not been defined, SIRT1 can prevent lipid peroxidation in retinal tissue cells and plays a critical protective role in the regulation of apoptosis [35].

Based on the fact that RSV is an activator of SIRT1, regulation of SIRT1 by RSV may be effective in preventing inflammation, lipid peroxidation, cell death and loss of endothelial function [15]. However, there are conflicting data on the subject. Contrary to previously published data showing significant effects in retinopathy associated with SIRT1 deficiency [4]. Michan et al. [25] has shown that increased SIRT1 gene expression does not alter pathological neovascularization or neuronal degeneration in mouse retinal neurons or vessels. In addition, it was reported that treatment with RSV, did not show a protective effect against the development of retinopathy [25]. It has been previously reported that a 16-fold increase in SIRT1 in hippocampal mouse neurons has no effect on synaptic plasticity and learning and memory [26]. It has been reported that increasing SIRT1 over 8 times in the heart may have a negative effect on cardiac functions [3]. Studies in different mouse models of human diseases have shown that the high level of increase in SIRT1 gene activity does not cause protective effects, whereas moderate SIRT1 gene activation may be protective [26].

As a result, RSV was used as a preventive treatment against diabetic retinopathy. However, the mechanisms underlying this protective effect are not fully elucidated. The aim of this study was to investigate how RSV supplementation affects retinal SIRT-1 levels and tissue damage in diabetic elderly female rats.

\section{Materials And Methods}

\section{Animal Material and Groups}

This study was carried out on 24 adult old female Wistar rats (16 months old) obtained from Selcuk University Experimental Medicine Research and Application Center. The rats were fed ad libitum and kept 
in 12-h light/dark cycle. The study protocol was approved by the ethics committee of the same center (2019-6). A total of 24 elder female Wistar rats were divided into 4 equal groups as follows:

Group 1, Control Group $(n=6)$ : The group fed with standard diet in which no administration was applied.

Group 2, Resveratrol Group ( $\mathrm{n}=6$ ): The group given intraperitoneal (ip) RSV ( $5 \mathrm{mg} / \mathrm{kg} / \mathrm{day}$ ) for 4 weeks in addition to the normal diet.

Group 3, Diabetes group ( $\mathrm{n}=6)$ : The group in which diabetes was induced by $40 \mathrm{mg} / \mathrm{kg}$ of ip Streptozotocin (STZ).

Group 4, Diabetic Resveratrol Group $(n=6)$ : The group in which diabetes was induced by ip STZ (40 $\mathrm{mg} / \mathrm{kg}$ ) and then RSV supplemented for 4 weeks ( $5 \mathrm{mg} / \mathrm{kg} / \mathrm{day}$ ).

\section{Experimental Diabetes}

In order to induce experimental diabetes, the rats in groups 3 and 4 were injected ip STZ (Sigma S-0130) of $40 \mathrm{mg} / \mathrm{kg}$. 6 days after the injections, blood glucose levels from the tail vein of the animals were measured using a diagnostic glucose kit. Rats with a blood glucose of $300 \mathrm{mg} / \mathrm{dL}$ and above were postulated as diabetic [14].

\section{Resveratrol Application}

RSV (R5010-Sigma) applied intraperitoneally to the rats in group 2 and group 4 daily at $5 \mathrm{mg} / \mathrm{kg}$ for four weeks.

\section{Biochemical Analysis}

Determination of Tissue Malondialdehyde (MDA): Retinal MDA levels were determined using the method of Mihara and Uchiyama [27]. Results are given as nmol/g tissue.

Tissue Glutathione (GSH) Analysis: Retinal GSH levels were measured using Ellman's method [31]. The data obtained were given as $\mathrm{mg} / \mathrm{gr}$ tissue.

\section{Real Time PCR Analysis}

Retinal mRNA levels were determined with a real time PCR system. The change in SIRT-1 expression due to diabetes and resveratrol treatment was measured using a real-time RT-PCR in eye tissue mRNA isolates.

\section{RNA isolation}

Total RNA was isolated from retinal tissue $(50 \mathrm{mg})$ using Nucleozol (Macherey-Nagel, Düren, Germany) RNA Isolation Kit according to the manufacturer's instructions. The purity and amount of RNA obtained 
was measured using a SMA1000 model spectrophotometer (Merinton, China) device. In addition, isolated RNA were run in $1 \%$ agarose gel to display specific $18 \mathrm{~S}$ and $28 \mathrm{~S}$ RNA bands.

\section{Real-Time Quantitative PCR Analysis}

The cDNA was obtained with the Bio-Rad (California, USA) cDNA synthesis kit using $1 \mu \mathrm{g}$ of RNA of each sample. The cDNA mix, with a total volume of $20 \mu \mathrm{l}$, contained $1 \mu \mathrm{g}$ of RNA, $4 \mu \mathrm{l}$ of cDNA master buffer, and $1 \mu \mathrm{l}$ of Reverse transcriptase enzyme. The obtained cDNAs was used for quantitative real-time PCR amplification of the targeted genes and reference gene. The target and reference genes were synthesized in the manufacturer company SENTEGEN (Ankara, Turkey). The bases belonging to these primers are given in table 1.

\section{Table 1. Primers for real-time quantitative PCR}

\begin{tabular}{|lll|}
\hline Gene & Forward primer & Reverse primer \\
SIRT-1 & CATAGGTTAGGTGGCGAGTATG & GTTGGTGGCAACTCTGATAAATG \\
\hline B-actin & TGTGACGTTGACATCCGTAAAG & GGCAGTAATCTCCTTCTGCATC \\
\hline
\end{tabular}

Samples were amplified in a volume of $20 \mu \mathrm{l}$ reaction mix, with a concentration of $1 \mu \mathrm{l}$ of forward and reverse primers, $10 \mu \mathrm{l}$ of Lightcycler SYBR Green (Roche Diagnostics, Germany), $5 \mu \mathrm{l}$ cDNA, nuclease-free water to $20 \mu$ l.

For PCR, each sample was tested in triplicate and the results were normalized using the amplification of the same cDNAs using the reference genes-actin calculations with $\Delta \Delta \mathrm{Ct}$.

\section{Analysis of the results obtained}

Reference and target CT values of each sample obtained using the quantification analysis program of the Biorad connect device were taken. Calculations were made on the Delta CT formula and the results were obtained for statistical analysis.

\section{Statistical Evaluations}

Statistical analysis was performed using the SPSS statistical program. Results were defined as mean \pm standard deviation. Kruskal-Wallis variance analysis was used for comparison between groups and Mann-Whitney $U$ test was used for $p<0.05$ level. $P<0.05$ level was considered statistically significant.

\section{Results}


The highest retinal MDA values were in the diabetes group $(G 3)(p<0.05)$. Retinal MDA levels of the general control (G1), Control + RSV (G2) and Diabetes + Resveratrol (G4) groups were not different from each other (Fig. 1). The highest retinal GSH values were in the Diabetes + Resveratrol group (G4) $(p<$ 0.05). Retinal GSH levels of the general control (G1), Control + Resveratrol (G2) and Diabetes (G3) groups were not different from each other (Fig. 2).

The highest retinal SIRT1 expression values were in the Diabetes + resveratrol (G4) group $(p<0.05)$. The retinal SIRT1 expression values of the diabetes group (G3) were lower than $G 4(p<0.05)$, and higher than the General control (G1) and Control + RSV (G2) groups ( $p<0.05)$. Retinal SIRT1 expression values of the general control (G1) and Control + resveratrol (G2) groups were not different from each other (Fig. 3).

\section{Discussion}

\section{Discussion of Retinal Lipid Peroxidation Parameters}

In our study, the highest retinal tissue MDA values were in the diabetes group (G3). The retinal MDA levels of the other groups were not different from each other.

Although the pathogenesis of diabetic retinopathy is not certain, the oxidative stress caused by hyperglycemia plays an important role. The main pathology here is that excessively reactive oxygen species cannot be neutralized with antioxidants [33]. There is increasing evidence that retinal tissue damage occurring in DR triggers events that lead to progressive blindness. It was suggested that RSV may have therapeutic potential in DR due to its antidiabetic and oxidant damage preventive effects [34].

Free radicals increase in ischemia-reperfusion injury due to hypoxic damage in tissues, and membranerelated polyunsaturated fatty acids cause tissue damage by binding to free radicals [32]. MDA levels, an indicator of lipid peroxidation, increase in ischemia-reperfusion injury [32]. RSV, on the other hand, prevents tissue damage in ischemia-reperfusion injury with its antioxidant properties $[5,20]$. Based on this point, Deng et al. [7] reported that tissue damage in the ischemic rat retina can be prevented with resveratrol supplementation. This effect of resveratrol was associated with the decreased production of inflammatory mediators that cause tissue damage [7]. Moine et al. [29] showed that retinal tissue damage caused by oxidation and photo-oxidation reactions can be prevented with resveratrol supplementation. Similarly, it has been reported that the survival of retinal ganglion cells associated with ischemia-reperfusion injury has increased with resveratrol administration [23]. These results show that resveratrol can be used in the prevention of retinal tissue damage. In our study, we determined higher MDA levels in the retina of diabetic elderly rats compared to other groups, which reversed with RSV administration. This finding is consistent with the findings of the data above and emphasizing the antioxidant properties of RSV.

The highest retinal tissue GSH values were determined in the Diabetes + RSV group (G4). The retinal GSH levels were not different among other groups. Glutathione is an important endogenous antioxidant and plays a critical role in protecting against oxidative stress. It has been reported that low doses of RSV have 
a therapeutic effect in the liver by increasing GSH levels in ischemic tissue damage $[2,13]$. High blood sugar levels as a result of diabetes, diabetic retinopathy also increases retinal tissue damage and lead to fibrotic changes [11]. RSV prevents tissue damage that occurs in diabetic retinopathy [11]. A growing body of evidence is suggests the role of oxidative stress in age-related visual impairments. It is accepted that RSV can be a good candidate for the correction of age-related visual disorders, especially due to its antioxidant and anti-inflammatory activities [12].

In one study, four months of resveratrol administration ( $5 \mathrm{mg} / \mathrm{kg} /$ day) was shown to significantly reduce hyperglycemia in the retinal tissue and improve the retinal apoptosis in diabetic rats [33]. In the study we conducted, we found the highest retinal GSH values in the Diabetes + Resveratrol group. This results shows that resveratrol increasing antioxidant activity in diabetic rats

\section{Discussion of Retinal Sirtuin 1 Gene Expression}

Diabetic retinopathy is the most important known microvascular complication of diabetes, it can cause eye impairment and even complete loss of visual function. Chronic subclinical retinal inflammation has been shown to be the main contributor of many vascular lesions in diabetic retinopathy. Although actors such as proinflammatory cytokines and/or oxidative stress associated with hyperglycemia have not been clearly defined yet, they play a critical role in the development of diabetic retinopathy [28]. SIRT1 is a longlived gene that is thought to be critical in the development of advanced treatment methods due to its association with many events such as metabolism, aging, cancer and neurodegeneration [22]. Endothelial dysfunction and vascular inflammation caused by hyperglycemia is a precursor and a powerful predictor of diabetic retinopathy [22]. SIRT1 may be effective in preventing inflammation, lipid peroxidation, cell death, and loss of endothelial function seen in diabetic retinopathy [16]. Already previous relevant studies hypothesized that SIRT 1 could limit these dysfunctions seen in diabetic retinopathy [17]. Therefore, activation of SIRT1 gene expression by resveratrol is beneficial in preventing inflammation, lipid peroxidation, cell death, and loss of endothelial cell function, which are the common markers of diabetic retinopathy [15].

In our study, we obtained the highest retinal SIRT1 expression values in the diabetic (G4) group with resveratrol was applied. The retinal SIRT1 expression values of the diabetic group (G3) without resveratrol application were lower than group 4, but higher than the control groups (G1) and resveratrol supplemented group (G2).

Kowluru et al. [19] reported that SIRT1 expression is suppressed in diabetic retinopathy and the most important event leading to suppression in SIRT1 is increased tissue damage in the retina [19]. In the same study, it was suggested that preventing retinal SIRT1 inhibition may also prevent the development of diabetic retinopathy [19]. Beside being a powerful stimulant with antioxidant properties, RSV is an activator of SIRT1 [15]. Activation of SIRT1 by RSV also reacts to prevent tissue damage by suppressing inflammation and increasing antioxidant activity in various pathological conditions, including DR [17]. Mohammad et al. [28] showed that SIRT1 expression in vitreous samples of patients with diabetic retinopathy decreased compared to controls, and treatment with SIRT1 activators could protect retinal 
endothelial barrier dysfunction caused by diabetes. Resveratrol is thought to be useful in the treatment of diabetes mellitus and its complications [21]. Activation of SIRT1 is considered critical in the antidiabetic effects of RSV. SIRT1 activation leads to a decrease in the circulatory levels of proinflammatory cytokines and proapoptotic cells. Following the antioxidant system is becomes active. As a result, the antidiabetic effects of resveratrol are revealed. [21]. In our study, we found the highest increase in SIRT1 gene expression in diabetic rats supplemented with resveratrol. However, SIRT1 expression was higher in diabetic rats that are not given resveratrol compared to control groups. This finding contrasts with the reports $[19,28]$ where SIRT1 expression is reduced in diabetic retinopathy. In our study, the old female rats were used and a single dose STZ (40 mg/kg) was administered to animals to induce diabetes, which may be the reason for the increased SIRT1 expression in the diabetic group without RSV supplementation. In our study, it is certain that the increased SIRT1 expression in the diabetic elderly female rats compared to the control groups is not sufficient to prevent retinal tissue damage.

The findings of our study show that retinal oxidative stress can be prevented with resveratrol supplementation in diabetic elderly female rats. This protective effect of resveratrol administration in diabetic elderly female rats may occur by promoting retinal antioxidant activity through SIRT1 gene expression.

\section{Conclusion}

Resveratrol supplementation in diabetic elderly female rats prevented retinal tissue damage by increasing antioxidant activity through SIRT1 gene expression.

\section{Declarations}

Author contributions: AA, SBB, OU, EGM made substantial contributions to the conception or design of the work; or the acquisition, analysis, or interpretation of data; or the creation of new software used in the work; RM and AKB drafted the work or revised it critically for important intellectual content, approved the version to be published. The authors declare that all data were generated in-house and that no paper mill was used.

\section{Research Data Policy and Data Availability Statement}

The datasets generated during and/or analysed during the current study are available from the corresponding author on reasonable request.

Funding: This study was supported by the Scientific Research Projects Coordinatorship of Selcuk University (SUBAPK; project no. 19202021).

Compliance with Ethical Standards: This study was conducted in accordance with the Declaration of Helsinki. The study protocol was approved by the Experimental Animals Ethics Board of Selcuk 
University's Experimental Medicine Research and Application Center (2019-6). This research was performed on the animals (rat).

Conflict of interest: The authors declare that they have no potential conficts of interest to disclose.

\section{References}

1. Ahsan H (2015) Diabetic retinopathy-biomolecules and multiple pathophysiology. Diabetes Metab Syndr 9:51-54

2. Aktaş HS, Ozel Y, Ahmad S, Pençe HH, Ayaz-Adakul B, Kudas I, Tetik S, Şekerler T, Canbey-Göret C, Kabasakal L, Elcioglu HK (2019) Protective effects of resveratrol on hepatic ischemia reperfusion injury in streptozotocin-induced diabetic rats. Mol Cell Biochem 460:217-224

3. Alcendor RR, Gao S, Zhai P, Zablocki D, Holle E, Yu X, Tian B, Wagner T, Vatner SF, Sadoshima J (2007) Sirt1 regulates aging and resistance to oxidative stress in the heart. Circ Res 100:1512-1521

4. Chen J, Michan S, Juan AM, Hurst CG, Hatton CJ, Pei DT, Joyal JS, Evans LP, Cui Z, Stahl A, Sapieha P, Sinclair DA. Smith LE (2013) Neuronal sirtuin1 mediates retinal vascular regeneration in oxygeninduced ischemic retinopathy. Angiogenesis 16:985-992

5. Chi KK, Zhang WH, Chen Z, Cui Y, He W, Wang SG, Zhang C, Chen J, Wang GC (2016) Comparison of quercetin and resveratrol in the prevention of injury due to testicular torsion/detorsion in rats. Asian $\mathrm{J}$ Androl 18:908-912

6. Coorey NJ, Shen W, Chung SH, Zhu L, Gillies MC (2012) The role of glia in retinal vascular disease. Clin Exp Optom 95:266-281

7. Deng C, Chen S, Li X, Luo H, Zhang Q, Hu P, Wang F, Xiong C, Sun T, Zhang X (2020) Role of the PGE2 receptor in ischemia-reperfusion injury of the rat retina. Mol Vis 26:36-47

8. Ding RB, Bao J, Deng CX (2017) Emerging roles of SIRT1 in fatty liver diseases. Int J Biol Sci 13:852-867

9. Farkhondeh T, Folgado SL, Pourbagher-Shahri AM, Ashrafizadeh M, Samarghandian S (2020) The therapeutic effect of resveratrol: Focusing on the Nrf2 signaling pathway. Biomed Pharmacother 127:110234

10. Gao S, Qin T, Liu Z, Caceres MA, Ronchi CF, Chen CY, Yeum KJ, Taylor A, Blumberg JB, Liu Y, Shang F (2011) Lutein and zeaxanthin supplementation reduces $\mathrm{H} 2 \mathrm{O} 2$-induced oxidative damage in human lens epithelial cells. Mol Vis 17:3180-3190

11. Giordo R, Nasrallah GK, Posadino AM, Galimi F, Capobianco G, Eid AH, Pintus G (2021) ResveratrolElicited PKC inhibition counteracts NOX-mediated endothelial to mesenchymal transition in human retinal endothelial cells exposed to high glucose. Antioxidants (Basel) 10:224

12. Goutham G, Manikandan R, Beulaja M, Thiagarajan R, Arulvasu C, Arumugam M, Setzer WN, Daglia M, Nabavi SF, Nabavi SM (2017) A focus on resveratrol and ocular problems, especially cataract: From chemistry to medical uses and clinical relevance. Biomed Pharmacother 86:232-241 
13. Hassan-Khabbar S, Vamy M, Cottart CH, Wendum D, Vibert F, Savouret JF, Thérond P, Clot JP, Waligora AJ, Nivet-Antoine V (2010) Protective effect of post-ischemic treatment with transresveratrol on cytokine production and neutrophil recruitment by rat liver. Biochimie 92:405-410

14. Havel PJ, Uriu-Hare JY, Liu T, Stanhope KL, Stern JS, Keen CL, Ahrén B (1998) Marked and rapid decreases of circulating leptin in streptozotocin diabetic rats: reversal by insulin. Am J Physiol 274:1482-1491

15. Hu Y, Liu J, Wang J, Liu Q (2011) The controversial links among calorie restriction, SIRT1, and resveratrol. Free Radic Biol Med 51:250-256

16. Hwang JW, Yao H, Caito S, Sundar IK, Rahman I (2013) Redox regulation of SIRT1 in inflammation and cellular senescence. Free Radic Biol Med 61:95-110

17. Karbasforooshan H, Karimi G (2018) The role of SIRT1 in diabetic retinopathy. Biomed Pharmacother 97:190-194

18. Kim WT, Suh ES (2010) Retinal protective effects of resveratrol via modulation of nitric oxide synthase on oxygen-induced retinopathy. Korean J Ophthalmol 24:108-118

19. Kowluru RA, Santos JM, Zhong Q (2014) SIRT1, a negative regulator of matrix metalloproteinase-9 in diabetic retinopathy. Invest Ophthalmol Vis Sci 55:5653-5660

20. Leonard SS, Xia C, Jiang BH, Stinefelt B, Klandorf H, Harris GK, Shi X (2003) Resveratrol scavenges reactive oxygen species and effects radical-induced cellular responses. Biochem Biophys Res Commun 309:1017-1026

21. Li J, Yu S, Ying J, Shi T, Wang P (2017) Resveratrol prevents ROS-Induced apoptosis in high glucosetreated retinal capillary endothelial cells via the activation of AMPK/Sirt1/PGC-1a pathway. Oxid Med Cell Longev 2017:7584691

22. Liu HN, Cao NJ, Li X, Qian W, Chen XL (2018) Serum microRNA-211 as a biomarker for diabetic retinopathy via modulating Sirtuin 1. Biochem Biophys Res Commun 505:1236-1243

23. Luo H, Zhuang J, Hu P, Ye W, Chen S, Pang Y, Li N, Deng C, Zhang X (2018) Resveratrol delays retinal ganglion cell loss and attenuates gliosis-related inflammation from ischemia-reperfusion injury. Invest Ophthalmol Vis Sci 59:3879-3888

24. Meng T, Xiao D, Muhammed A, Deng J, Chen L, He J (2021) Anti-inflammatory action and mechanisms of resveratrol. Molecules 26:229

25. Michan S, Juan AM, Hurst CG, Cui Z, Evans LP, Hatton CJ, Pei DT, Ju M, Sinclair DA, Smith LE, Chen J (2014) Sirtuin1 over-expression does not impact retinal vascular and neuronal degeneration in a mouse model of oxygen-induced retinopathy. PLoS One 9:e85031

26. Michan S, Li Y, Chou MM, Parrella E, Ge H, Long JM, Allard JS, Lewis K, Miller M, Xu W, Mervis RF, Chen J, Guerin KI, Smith LE, McBurney MW, Sinclair DA, Baudry M, de Cabo R, Longo VD (2010) SIRT1 is essential for normal cognitive function and synaptic plasticity. J Neurosci 30:9695-9707

27. Mihara M, Uchiyama M (1978) Determination of malonaldehyde precursor in tissues by thiobarbituric acid test. Anal Biochem 86:271-278 
28. Mohammad G, Abdelaziz GM, Siddiquei MM, Ahmad A, De Hertogh G, Abu El-Asrar AM (2019) Crosstalk between Sirtuin 1 and the proinflammatory mediator high-mobility group Box-1 in the regulation of blood-retinal barrier breakdown in diabetic retinopathy. Curr Eye Res 44:1133-1143

29. Moine E, Brabet P, Guillou L, Durand T, Vercauteren J, Crauste C (2018) New lipophenol antioxidants reduce oxidative damage in retina pigment epithelial cells. Antioxidants (Basel) 7:197

30. Robin A, Giovingo M (2021) Screening recommendations for diabetics. Dis Mon 2021:101116

31. Sedlak J, Lindsay RH (1968) Estimation of total, protein-bound, and nonprotein sulfhydryl groups in tissue with Ellman's reagent. Anal Biochem 25:192-205.

32. Sehirli O, Sener E, Cetinel S, Yüksel M, Gedik N, Sener G (2008) Alpha-lipoic acid protects against renal ischaemia-reperfusion injury in rats. Clin Exp Pharmacol Physiol 35:249-255

33. Soufi FG, Mohammad-Nejad D, Ahmadieh H (2012) Resveratrol improves diabetic retinopathy possibly through oxidative stress - nuclear factor kappaB - apoptosis pathway. Pharmacol Rep 64:1505-1514

34. Toro MD, Nowomiejska K, Avitabile T, Rejdak R, Tripodi S, Porta A, Reibaldi M, Figus M, Posarelli C, Fiedorowicz M (2019) Effect of resveratrol on in vitro and in vivo models of diabetic retinophathy: A systematic review. Int J Mol Sci 20:3503

35. Yao Q, Zhou Y, Yang Y, Cai L, Xu L, Han X, Guo Y, Li PA (2020) Activation of Sirtuin1 by lyceum barbarum polysaccharides in protection against diabetic cataract. J Ethnopharmacol 261:113165

36. Zeng K, Yang N, Wang D, Li S, Ming J, Wang J, Yu X, Song Y, Zhou X, Yang Y (2016) Resveratrol prevents retinal dysfunction by regulating glutamate transporters, glutamine synthetase expression and activity in diabetic retina. Neurochem Res 41:1050-1064

\section{Figures}




\section{Retinal MDA (nmol/gr tissue)}

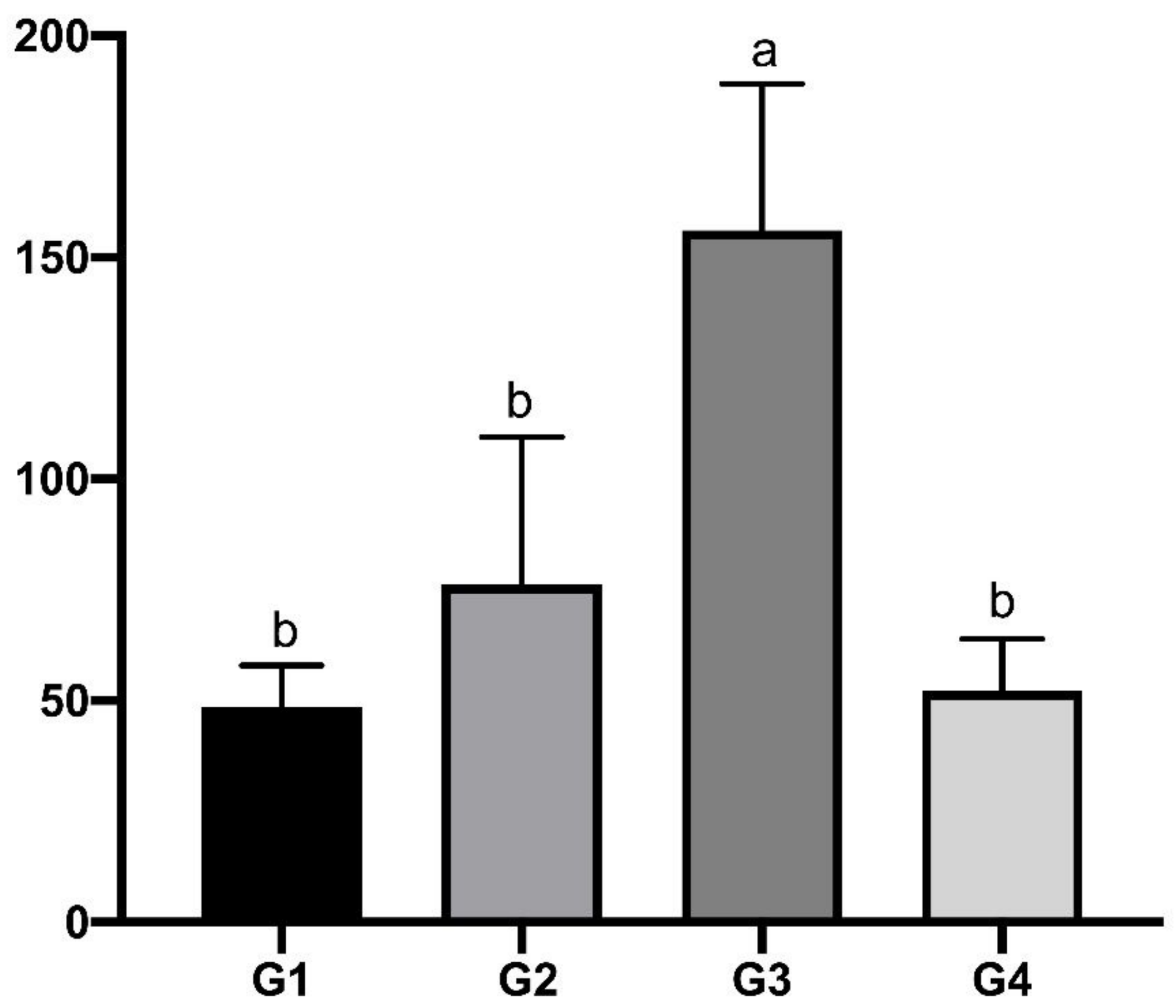

Figure 1

Retinal MDA Levels of Study Groups Differences between the means with different letters in the same column are significant $(p<0.05),(a>b)$. 


\section{Retinal GSH (mg/gram/tissue)}

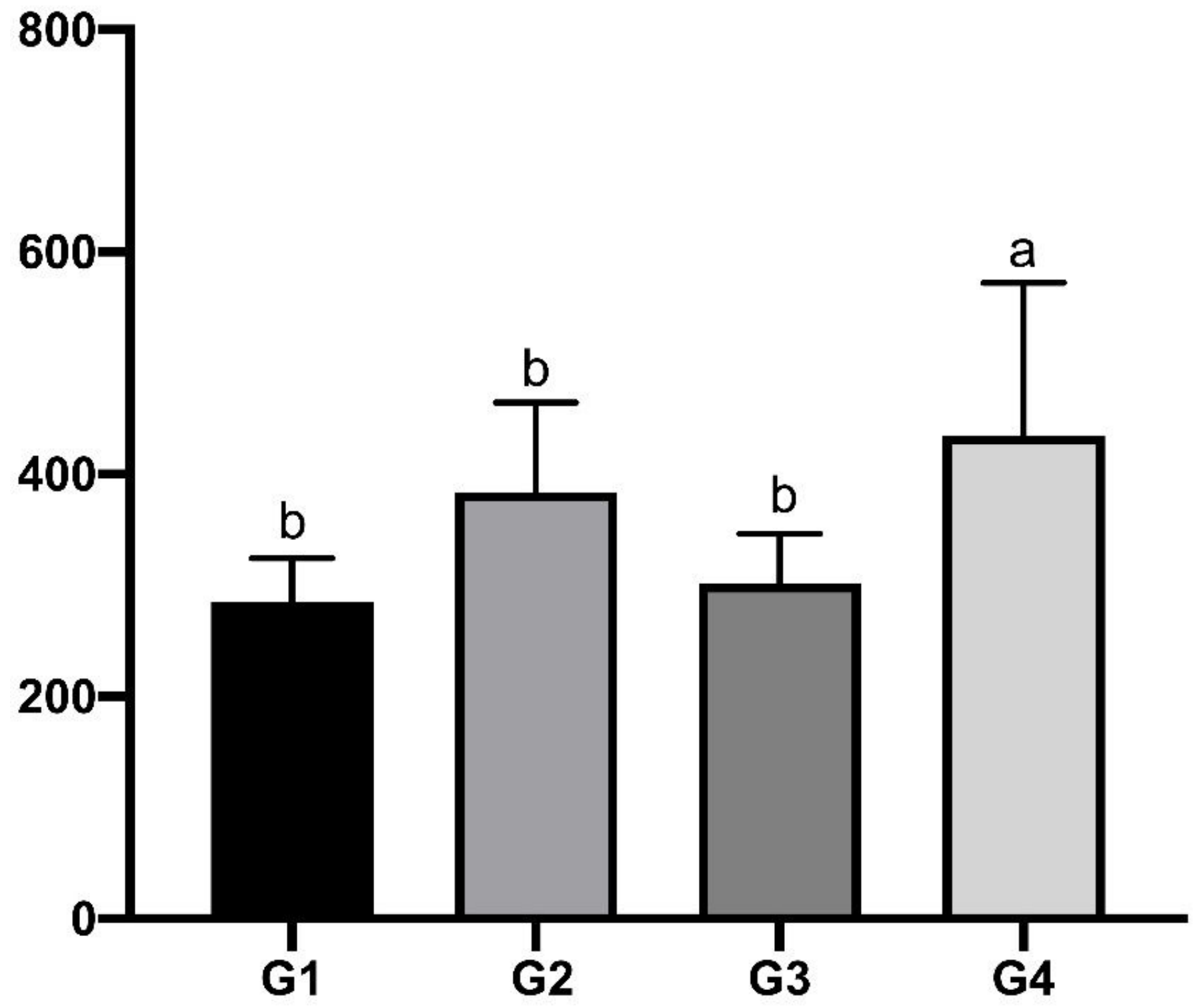

Figure 2

Retinal GSH Levels of Study Groups Differences between the means with different letters in the same column are significant $(p<0.05),(a>b)$. 


\section{SIRT1 Gene Activation $\left(2^{-\Delta \mathrm{CT}}\right)$}

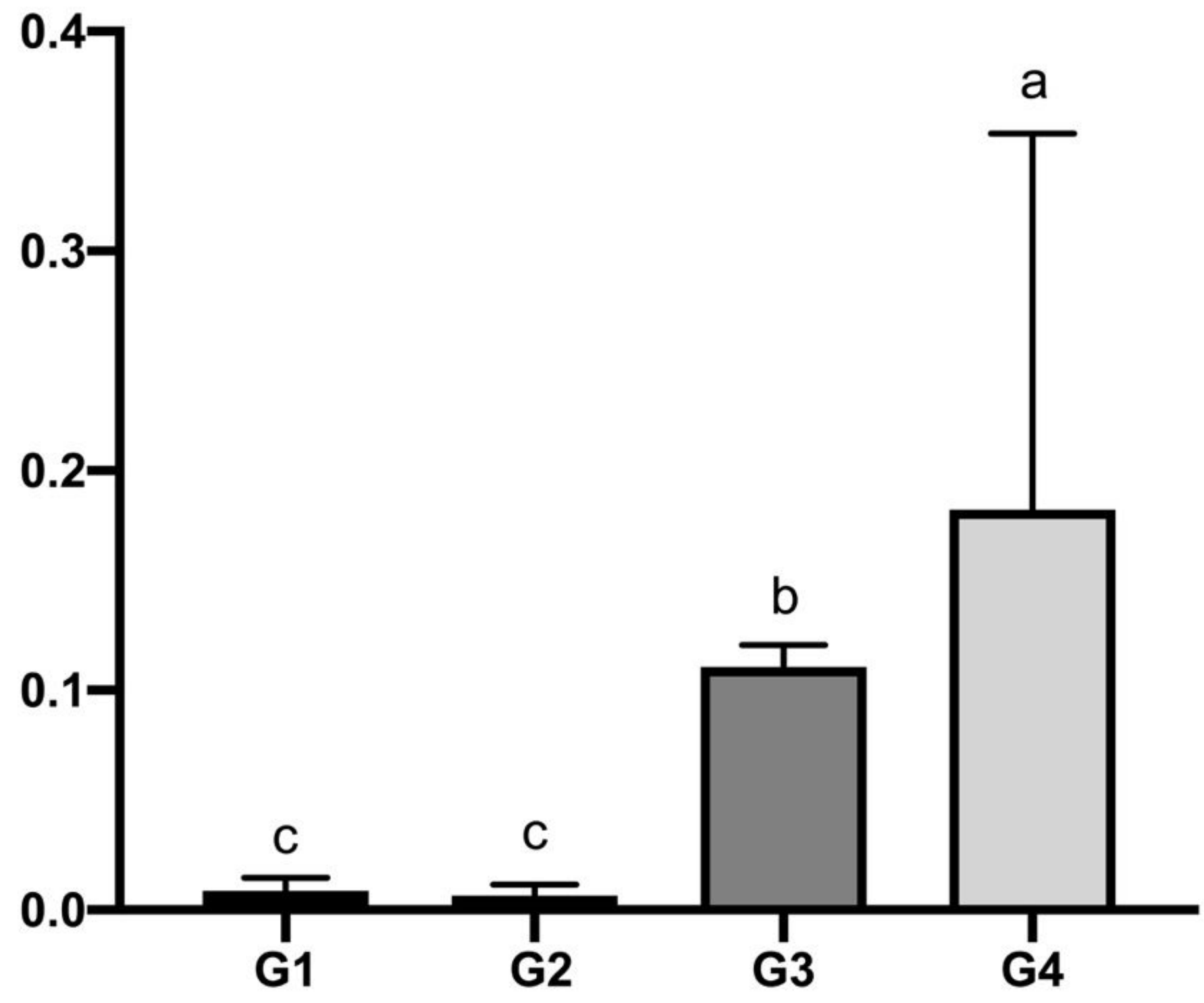

Figure 3

Retinal SIRT1 Gene Expression of StudyGroups (2- $\Delta \mathrm{CT}$ ) Differences between the means with different letters in the same column are significant $(p<0.05),(a>b>c)$. 